\title{
Identifying Opportunities for Workflow Automation in Health Care: Lessons Learned from Other Industries
}

\author{
Teresa Zayas-Cabán ${ }^{1}$ Saira Naim Haque ${ }^{2}$ Nicole Kemper ${ }^{3}$
}

1 Office of the National Coordinator for Health Information Technology, Washington, District of Columbia, United States

2 RTI International, Research Triangle Park, North Carolina, United States

${ }^{3}$ Clinovations Government + Health, Washington, District of Columbia, United States

Appl Clin Inform 2021;12:686-697.
Address for correspondence Teresa Zayas-Cabán, PhD, National Library of Medicine, National Institutes of Health, BG 38A RM 4S415, 8600 Rockville Pike, Bethesda, MD 20894, United States (e-mail: Teresa.ZayasCaban@nih.gov).

\section{Abstract \\ Keywords \\ - automation \\ - clinical care \\ - clinical information systems \\ - computing \\ - health care delivery \\ - health information technology \\ - informatics \\ - policy \\ - systems analysis \\ - workflow}

Background Workflow automation, which involves identifying sequences of tasks that can be streamlined by using technology and modern computing, offers opportunities to address the United States health care system's challenges with quality, safety, and efficiency. Other industries have successfully implemented workflow automation to address these concerns, and lessons learned from those experiences may inform its application in health care.

Objective Our aim was to identify and synthesize (1) current approaches in workflow automation across industries, (2) opportunities for applying workflow automation in health care, and (3) considerations for designing and implementing workflow automation that may be relevant to health care.

Methods We conducted a targeted review of peer-reviewed and gray literature on automation approaches. We identified relevant databases and terms to conduct the searches across sources and reviewed abstracts to identify 123 relevant articles across 11 disciplines. Results Workflow automation is used across industries such as finance, manufacturing, and travel to increase efficiency, productivity, and quality. We found automation ranged from low to full automation, and this variation was associated with task and technology characteristics. The level of automation is linked to how well a task is defined, whether a task is repetitive, the degree of human intervention and decision-making required, and the sophistication of available technology. We found that identifying automation goals and assessing whether those goals were reached was critical, and ongoing monitoring and improvement would help to ensure successful automation.

Conclusion Use of workflow automation in other industries can inform automating health care workflows by considering the critical role of people, process, and technology in design, testing, implementation, use, and ongoing monitoring of automated workflows. Insights gained from other industries will inform an interdisciplinary effort by the Office of the National Coordinator for Health Information Technology to outline priorities for advancing health care workflow automation. received

February 9, 2021

accepted after revision

May 25, 2021
DOI https://doi.org/

10.1055/s-0041-1731744. ISSN $1869-0327$. (c) 2021. The Author(s).

This is an open access article published by Thieme under the terms of the Creative Commons Attribution-NonDerivative-NonCommercial-License, permitting copying and reproduction so long as the original work is given appropriate credit. Contents may not be used for commercial purposes, or adapted, remixed, transformed or built upon. (https://creativecommons.org/ licenses/by-nc-nd/4.0/) Georg Thieme Verlag KG, Rüdigerstraße 14, 70469 Stuttgart, Germany 


\section{Background and Significance}

Twenty years ago, the National Academy of Medicine published two landmark reports ${ }^{1,2}$ highlighting systemic quality and safety deficiencies in United States health care and outlining strategies to address them. Despite investments and innovations, challenges with inefficient workflows, ${ }^{3}$ variable quality, ${ }^{4}$ patient safety, ${ }^{5}$ and poor outcomes remain. ${ }^{4}$ Although different care delivery models and technological solutions offer great promise, the use of automation may also offer opportunities to address some of these challenges. Automation, defined as "the creation and application of technology to monitor and control the delivery of products and services," ${ }^{6}$ has been successfully implemented in other industries to improve quality, productivity, efficiency, timeliness, effectiveness, and operational safety, as well as to reduce costs and deliver better value to customers.

In health care, there is an opportunity to employ relevant techniques to better automate workflows (i.e., "the sequence of physical and mental tasks performed by various people within and between work environments" ${ }^{7}$ to reduce burden on providers and staff, improve quality and efficiency, and deliver better value to patients and caregivers. ${ }^{8,9}$ Investments have been made to automate administrative and operational workflows in health care, for example, reducing time spent scheduling appointments ${ }^{10}$ and minimizing manual medical record abstraction for automated calculation of quality metrics. ${ }^{11}$ However, there are opportunities to improve the initiatives underway and leverage automation for treatment and care delivery, population health, patient safety surveillance and reporting, and analytics to benefit stakeholders across the health care continuum.

Recent advances in modern computing, including the advent of the internet of things, increased computing power, and access to information, have created opportunities for automation across industries. ${ }^{12-21}$ Information access and sharing and computational advances facilitate faster processing times and have made automation innovations, such as ride sharing or food ordering applications, possible. Aviation has invested in automation for decades, using it across operations in everything from scheduling and managing flights and crews to flying an aircraft. Automation has facilitated manufacturing advances in production scheduling, assembly line, ${ }^{22}$ robotics, ${ }^{23-25}$ and quality control. ${ }^{22,26}$ In finance, many banking processes are automated to benefit institutions and customers. ${ }^{27}$ Several of these industries have had automation in place longer and gone through more advancement, as compared with health care. ${ }^{9}$ Health care generally has similar workflows to these industries, including preparing for appointments and procedures, sharing financial and health data across institutions, organizing and assigning the human and supply resources necessary to deliver care, and reorganizing and reassigning those resources for expected and unexpected occurrences. Nonhealth care industries may offer useful examples and lessons learned to inform and advance implementation of automation in health care. In addition, now that the United States health care system has a more extensive health information technology (IT) infrastructure and increased availability of electronic health data, ${ }^{28,29}$ the opportunity to advance workflow automation in health care is far greater than it was 10 years ago.

As the federal agency that coordinates health IT policy and leverages modern computing to advance health information exchange across the United States, the Office of the National Coordinator for Health Information Technology $(\mathrm{ONC})^{30}$ is leading a collaborative and interdisciplinary effort to outline priorities for health care workflow automation. To inform this effort, we reviewed the literature to understand how automation is used across industries and disciplines and to identify lessons learned that could be applied in health care. ${ }^{31,32}$ This article describes findings from the literature review and implications for the use of automation approaches in health care, and it presents considerations to identify workflows and to implement relevant automation approaches.

\section{Objectives}

The literature review has two main objectives. First, to identify current approaches in workflow automation across industries. Second, to synthesize evidence across literature to identify (1) opportunities from nonhealth care industries that could be employed or applied in health care to advance workflow automation; and (2) considerations for designing and implementing workflow automation across industries and disciplines that may be relevant to health care.

\section{Methods}

To better understand workflow automation in other industries and identify lessons learned applicable to health care, we conducted a targeted review focused on key, relevant work. Sources included peer-reviewed journals and such gray literature as issue briefs, government reports, and conference proceedings and presentations that were published in English. We developed a targeted list of search terms most relevant to addressing the topic to stay focused on the overall objectives, given the breadth of the area being investigated, as shown in - Table 1. The gray literature search included web searches for colloquial terms related to the search terms. We identified relevant databases to search the peer-reviewed literature, some of which include gray literature and appear in both sections of - Table 1 . We searched literature from 2014 to 2019. A Master of Library Sciencetrained librarian provided input into the keywords and conducted searches.

The search yielded 139 articles. Two health informatics experts screened articles to ensure that they met the overall objectives by review of abstracts, and 123 were deemed relevant for inclusion based on the focus of this effort. The excluded articles did not have workflow as a central focus or were primarily focused on technology. Results from web searches were screened in a similar manner.

Resources reviewed spanned a variety of industries and disciplines. Two health informatics experts used the Higher 
Table 1 Databases and keywords for literature review (2014-2019)

\begin{tabular}{|c|c|}
\hline Sources searched & Search terms \\
\hline \multicolumn{2}{|l|}{ Peer-reviewed literature } \\
\hline $\begin{array}{l}\text { - Business Source Corporate } \\
\text { - Cumulative Index to Nursing and Allied Health Literature } \\
\text { - Cochrane Central Library } \\
\text { - Google Scholar } \\
\text { - Library, Information Science and Technology Abstracts } \\
\text { - PsycINFO } \\
\text { - PubMed } \\
\text { - Web of Science }\end{array}$ & $\begin{array}{l}\text { (workflow* OR "work flow*" OR process OR processes OR } \\
\text { (work* AND flow*)) AND automat* AND ("health IT" OR "health } \\
\text { information technology*" OR health care OR "health care" OR } \\
\text { "information system*" OR agriculture* OR "food production" } \\
\text { OR transportation OR hospitality OR industry* OR business* OR } \\
\text { "operations research" OR "industrial engineer*" OR "human } \\
\text { factor*" OR ergonomic*) AND success* OR solution* OR "case } \\
\text { study" OR "case studies" OR evaluate OR review* }\end{array}$ \\
\hline \multicolumn{2}{|l|}{ Gray literature } \\
\hline $\begin{array}{l}\text { Searches in the Cochrane Central library and Web of } \\
\text { Science }\end{array}$ & $\begin{array}{l}\text { Web searches based on the search terms and colloquial terms } \\
\text { for the search terms }\end{array}$ \\
\hline
\end{tabular}

Education Statistics Agency (HESA) Joint Academic Coding System (JACS) 3.0 principal subject codes (highest level) to characterize the literature that was reviewed and to organize and count representation across disciplines. ${ }^{33}$ The HESA JACS codes represent an open source classification of higher education information for data users. Each resource was reviewed by at least one health informatics expert. Review included extracting key points from each resource related to people, process, or technology; ${ }^{34}$ factors that have been identified in the literature as relevant to the design, implementation, and use of technology in work places. Themes across resources were identified related to approaches to automation, opportunities for applying workflow automation in health care, and implementation considerations. The experts met weekly during the literature review to identify key points and themes, resolve any differences in perspectives, and refine key points.

\section{Workflow Automation Approaches across Industries}

Our review sought examples of automation that could apply to health care. We identified key examples of the use of automation in other industries, a continuum for automation, the role of technology across that continuum, factors that guide workflow selection for automation, and considerations in designing and implementing automation. JACS areas represented in the reviewed literature are in -Table 2. - Supplementary Table S1 (available in the online version) includes a detailed mapping of all the reviewed articles to the JACS areas. There were several JACS areas representing a broad range of disciplines, with the majority of articles from computer science and subjects allied to medicine, engineering, and technology.

Analysis of the 123 articles yielded six themes: use of workflow automation in other industries, importance of establishing goals for automation, strategies for identifying and selecting workflows to automate, the automation continuum, consideration for designing and implementing workflow automation, and ongoing monitoring and continuous improvement. A discussion of each of the themes follows.

\section{Workflow Automation in Other Industries}

Automation was used for several workflows across a range of industries. Some industries, such as manufacturing and banking and finance, have long-standing histories of using automation. ${ }^{27,35}$ Other industries are newer to automation, including legal consultation, ${ }^{36}$ hospitality, ${ }^{37}$ and transportation (e.g., ride sharing). ${ }^{38}$ Across industries, a variety of workflows were automated, including accounting functions, ${ }^{27,39}$ document routing, ${ }^{40}$ work and resource allocation, ${ }^{41,42}$ quality monitoring and control, ${ }^{43-48}$ report generation, ${ }^{35,49}$ and supply chain and logistics management. ${ }^{40-52}$ In addition, automation has been used for physical and chemical processes, ${ }^{45,53}$ and biologic and laboratory pre- and postanalytic activities. ${ }^{54-57}$

Examples of automation found in the literature focused primarily on automating workflow at a single organization

Table 2 Mapping of included literature to Joint Academic Coding System area based on the Joint Academic Coding System 3.0 principal subject code

\begin{tabular}{|l|l|}
\hline JACS areas & $\begin{array}{l}\text { Articles by } \\
\text { JACS area }\end{array}$ \\
\hline Computer science & 35 \\
\hline Subjects allied to medicine & 21 \\
\hline Engineering and technology & 20 \\
\hline Medicine and dentistry & 19 \\
\hline Business and administrative studies & 13 \\
\hline Biological sciences & 7 \\
\hline Mass communications and documentation & 3 \\
\hline Agriculture and related subjects & 2 \\
\hline Architecture, building, and planning & 1 \\
\hline Education & 1 \\
\hline Social studies & 1 \\
\hline Total articles included & 123 \\
\hline
\end{tabular}

Abbreviation: JACS, Joint Academic Coding System. Note: Reprinted with permission from the Office of the National Coordinator for Health Information Technology. ${ }^{32}$ 
(e.g., streamlining processes in manufacturing for aerospace ${ }^{58}$ or streamlining response to citizen requests in a municipality) 12 or across an enterprise (e.g., allocating work and sharing associated documents in a credit union with multiple branches $)^{27}$ versus efforts focused on advancing automation for an industry as a whole. The literature was characterized by documentation of successful examples of automation, rather than failed attempts. The remaining themes denote ways to ameliorate potential problems that can be caused by automation, which can be applied to health care. ${ }^{59}$

\section{Establishing Goals for Workflow Automation}

Organizations pursue automation for several reasons, including saving time, improving productivity, and enhancing quality. ${ }^{21}$ For example, one business office sought to reduce employee time when conducting tasks within a workflow, such as activity tracking and providing targeted employee guidance through automation. ${ }^{23}$ Similarly, automation of workflows in dairy farming was pursued to improve milk output while reducing manual effort for milking. ${ }^{60}$

The importance of identifying clear goals for automation and gaining consensus about them among stakeholders cuts across industries and workflows. ${ }^{61}$ For example, in aerospace engineering, end-users identified a workflow that was highly repetitive and manual as a candidate for automation to save time and improve efficiency. ${ }^{61}$ This example highlights the importance of engaging stakeholders who will be impacted by workflow automation and aligning automation goals with workflows selected for automation. ${ }^{23}$

Automation goals may not be met if a clear set of goals is not identified and stakeholders impacted by automation are not engaged. Reasons for not achieving those goals include selection of processes that are not suitable for automation, such as those listed in -Table 3, selection of technology not suitable for the workflow, a lack of suitable available technology, or use of available technology that is improperly applied. In addition, insufficient understanding and response to organizational aspects of implementation can lead to unmet automation goals, ${ }^{9}$ such as stakeholder concerns about losing the ability to interact with or access decision-making authority $22,62-67$ and worries related to the impact on quality, safety, privacy, and security. ${ }^{48,68-74}$

\section{Strategies for Identifying and Selecting Workflows to Automate}

Several common characteristics of workflows were found in the literature that can be used to identify and select suitable workflows to automate. In particular, the decision to automate a particular workflow and to what degree is based on several factors, summarized in - Table $3 .{ }^{63,75,76}$ In contrast, the literature revealed characteristics associated with workflows that are more difficult to automate, summarized in -Table 3.8,12,18,27,39,54,62,77-79 Careful selection with these characteristics in mind can help to prevent some of the documented problems that automation can cause $\mathrm{e}^{59}$ across industries, including health care.

Identifying workflows and determining suitability for and degree of automation are typically based on analysis of three aspects. ${ }^{63,75,80}$ The first relates to people and the degree of human intervention required. The second aspect relates to process-the characteristics of the tasks within a workflow and repetition of workflows with clear roles and responsibilities. The third aspect relates to technology and the availability of tools to support a range of workflows for full or partial automation.

\section{Automation Continuum}

As summarized in - Fig. 1, we found automation implementations ranging from workflows, where humans continued to be significantly involved, to semi- and fully automated workflows with little or no human involvement. Semi-automated workflows included content management of library workflows to highlight actions that should be taken manually; ${ }^{81}$ client profile development in banking to identify which might need personalized attention; ${ }^{82}$ and quality assurance processes in the automotive industry to identify outlier assembled parts that need human review. ${ }^{43}$ Some examples of fully automated workflows included production scheduling and workload management in a manufacturing plant ${ }^{58}$ and optimizing production cycles in biomanufacturing. ${ }^{44,47}$

The degree of automation was generally linked to the complexity of tasks within a workflow, types of decision rules involved for the workflow, sophistication of technology needed, technology availability, and human intervention needed. ${ }^{64,83-85}$ Determining the degree of automation requires reviewing workflows and their context. For example, in a semi-conductor manufacturing plant, workflows across the production line were reviewed to determine which could be fully automated, semi-automated, or should remain manual. ${ }^{22}$ Workflows that were fully automated were typically simple parts assembly; workflows that were partially automated involved initial assembly with human finishing and initial quality assurance; and workflows that remained manual involved review of items

Table 3 Workflow characteristics that promote or challenge automation

\begin{tabular}{|l|l|}
\hline Characteristics that promote automation & Characteristics that challenge automation \\
\hline - Manual data entry & - Complex decision rules that are tacit and inconsistently followed \\
- High frequency and/or repetition & - Inconsistent data requirements \\
- Clearly defined independent and dependent & $\begin{array}{l}\text { - Independent and dependent variables that influence decision-making } \\
\text { variables for modeling }\end{array}$ \\
- Clear roles and responsibilities & - Deviation from “ideal" workflows in practice \\
\hline
\end{tabular}




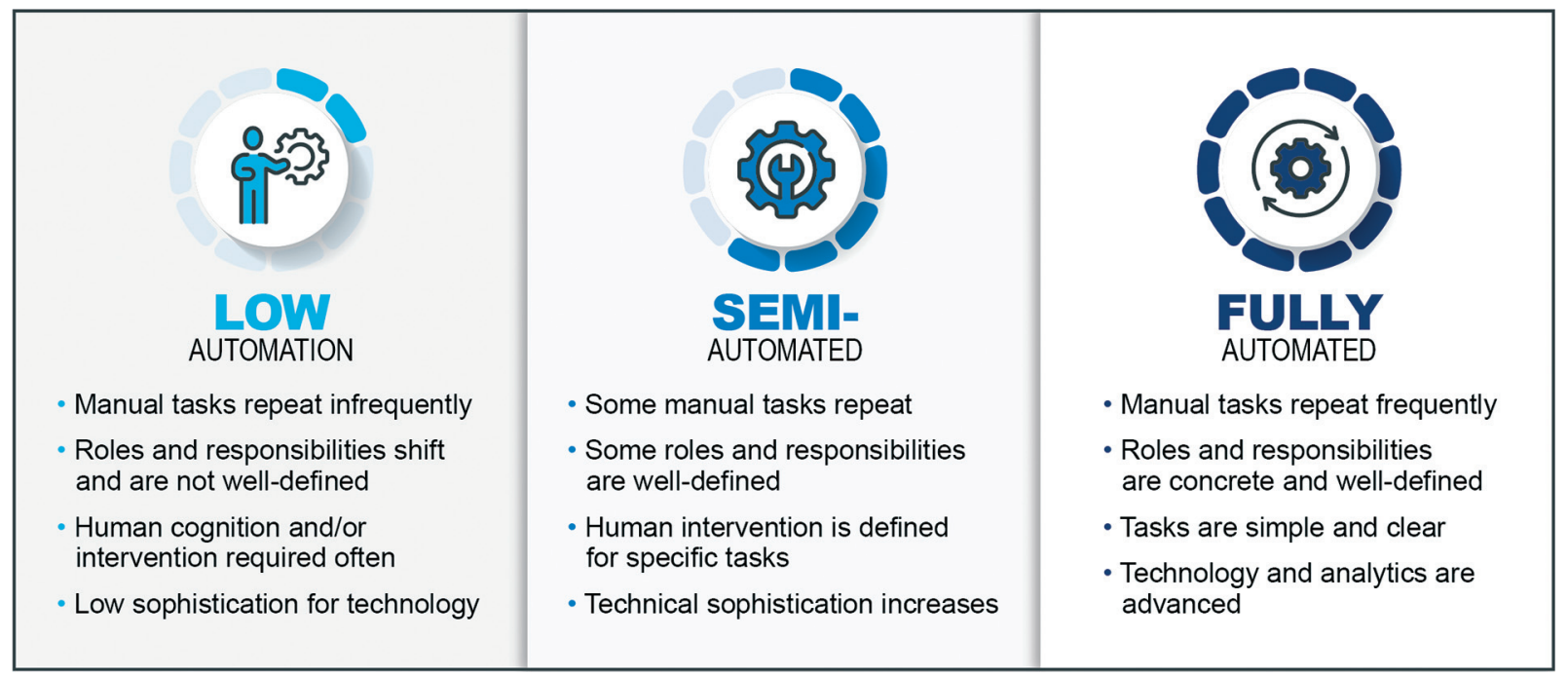

Fig. 1 Automation spectrum and workflow and technology characteristics. Adapted with permission from the Office of the National Coordinator for Health Information Technology. ${ }^{32}$

identified as having possible defects from a quality assurance review. Similarly, additional examples of fully automated workflows in other industries found in the literature include labor allocation in a distribution center based on volumes, ${ }^{50}$ robotic process automation to address routine workflows in an office with repetitive business tasks, ${ }^{35}$ and water treatments that were automatically tracked and adjusted based on changes in salination level. ${ }^{65}$

Several technology capabilities and characteristics noted in the literature that support the continuum of automation are listed in -Table 4 . These characteristics occur across industries and are relevant to health care. Characteristics and capabilities to consider when selecting technology to support workflow automation range from attending to data systems and how they interoperate and are integrated, technical infrastructure and its ability to support automation activities or processes, the ability to effectively present knowledge and information visually, design and needs of decision rules, and security needs.

Table 4 Workflow automation technology considerations

1. Number and type of systems housing relevant data to support workflows ${ }^{86,87}$

2. Interoperability between systems in which relevant data are stored across types and formats ${ }^{86-88}$

3. Technical infrastructure, including cloud-based capabilities, analytics, and computing power ${ }^{45,46,69,79,89}$

4. Data visualization capabilities available for dashboards and other visual representations of data $42,57,88$

5. Complexity of decision rules required ${ }^{41,79,90}$

6. Communication and networking considerations, such as bandwidth $^{13}$

7. Integration of automated workflow with other organizational information systems $45,46,82,91$

8. Security considerations within and across systems ${ }^{91}$

\section{Considerations for Designing and Implementing Workflow Automation}

When designing and implementing workflow automation, aspects of people, process, and technology found in the literature may offer important lessons to apply workflow automation in health care.

People aspects include attaining leadership support and ensuring that staff throughout the organization is aware of the institutional commitment to automation. ${ }^{39,92}$ Another key implementation consideration is identifying those who are participants in or impacted by workflows being considered for automation or being automated, and engaging their support and participation as these workflows are identified and redesigned and automation is implemented. ${ }^{27}$ Engaging stakeholders includes obtaining their input as roles and responsibilities are documented, training them, eliciting their feedback during implementation of automated workflows, and proactively addressing concerns. ${ }^{61,70,93-95}$

Aspects of this process include documenting, analyzing, and redesigning workflows. ${ }^{96}$ Engaging stakeholders throughout workflow redesign can help to support the desired automated end state. ${ }^{97}$ Documenting workflows involves identifying activities, intersections with other workflows, constraints, dependencies, and resources. ${ }^{72,96}$ Analyzing workflows involves reviewing the documented workflow to support redesign. ${ }^{97}$ Redesigned workflows include changes to documentation to support the desired automated end state. ${ }^{58,98}$ The redesigned workflows can be used as a basis for training and launch of the automated workflows. ${ }^{99,100}$ After launch, keeping stakeholders engaged and making relevant changes was noted across industries. ${ }^{47,101}$

Workflow automation involves aspects of technology such as selection and usability. Technology capabilities and characteristics identified from the literature that support the continuum of automation across industries that may be relevant to health care are listed in - Table 4. These represent characteristics and capabilities to consider when selecting 
technology to support workflow automation. One step is identifying available technologies to ensure that technology aligns with stakeholder needs and the redesigned workflow. ${ }^{45,48}$ This involves ensuring that information can be shared across systems. ${ }^{83,87}$ If information is not interoperable, that may influence automation due to manual intervention being required. ${ }^{87}$ Another aspect is reviewing metrics to determine whether the expected improvements occurred $^{44,56,102}$ and, if they did not, to explore why and make changes accordingly. ${ }^{103}$ Changes that may be needed might include retraining, workflow changes, changes in decision- rules, or technology changes. ${ }^{39,44,57,85,104}$

\section{Ongoing Monitoring and Continuous Improvement}

As workflow automation is implemented and used, ongoing monitoring and analysis are needed. This involves an understanding of how best to deploy technology to manage workflow and examination of how automation is used to make any needed adjustments in design or implementation. ${ }^{49}$ User satisfaction with the system and the overall design and implementation process are important to consider when evaluating the alignment of technologies and workflows. ${ }^{60,105}$ Ensuring user satisfaction involves assessing usability of systems. ${ }^{67}$ Ongoing analysis involves assessing the physical structure and the intersection of technology, workflow automation, and physical layout. ${ }^{86}$ It is important to continue to refine the boundaries of automation in practice and make changes to accommodate where human interaction might be needed. ${ }^{52,101}$ Human interaction may involve reviewing error reports, duplicate records, or exceptions that require manual intervention for further analysis. ${ }^{39,57,106}$ Outcomes may involve changes in the degree of automation, changes in technology, or changes in decision support to inform automation. ${ }^{54}$

One common theme found in the literature was the need to continue monitoring and reviewing automated workflows. ${ }^{96}$ This involves returning to the original automation goals and reviewing progress. One way to do this is to continually engage with stakeholders and end-users to obtain their perspectives. ${ }^{101}$ Another is to identify metrics related to the original goals and regularly review progress. ${ }^{96,106}$ Ongoing measurement and stakeholder engagement were noted across industries and types of workflows to identify changes to optimize automation. ${ }^{56,107,108}$

\section{Opportunities and Considerations for Health Care Delivery}

The findings from the literature point to several considerations for automation of health care workflows. Industrywide gains from automation may require broad collaboration in a manner that other industries have undertaken. $61,102,109$ The types of workflows selected for automation vary based on goals, ${ }^{41,50}$ organizational factors, ${ }^{9,15}$ the level of human intervention, ${ }^{39}$ and characteristics of the workflow and technology being considered. ${ }^{61,110}$ Although health care tasks may differ from tasks performed in other industries, and thus, the automation approaches from other industries may not be directly applicable; there are lessons learned regarding how to approach automation that may be important to consider in the application of automation approaches in health care. Although health care has made use of automation, it is generally employed in administrative and operational processes such as billing, ${ }^{98}$ compound preparation, ${ }^{45,111}$ or delivery of medications, meals, or linens ${ }^{112}$ with the purpose of reducing "no-show" rates for scheduled appointments, increasing patient throughput, and reducing the burden of operational workflows. There are examples of automation of clinical care tasks such as screening processes, ${ }^{113}$ transmitting results and other communications, ${ }^{114}$ and application of clinical guidelines ${ }^{115,116}$ that use health IT. There is an opportunity to explore different degrees of automation for workflows that have experienced less automation. Automating clinical data review by using technology to identify-(1) gaps and locate missing information or data housed in third-party systems or (2) identify and resolve duplicate data from multiple sources-could support the cognitive tasks involved in treatment and care delivery workflows, such as setting follow-up reminders, communicating with consulting clinicians, checking the status of immunizations administered, reviewing data for an upcoming encounter at a clinic or hospital, and ensuring critical items are addressed prior to discharge. Continuous, automated data monitoring, and alerting across disease registries, as well as nonclinical datasets related to social determinants of health, could streamline population health interventions and communications. The use of standards and machine learning approaches could reduce the burden of surveillance workflows, such as medical record abstraction, as well as reporting and transmission workflows for quality, safety, and public health data. These technologies can use carefully crafted and tested algorithms that collect, organize, analyze, and present data to automate analytics workflows. In addition, there may be opportunities to employ automation to expand, refine, and streamline other administrative and operational workflows regarding care logistics, supply chain, preauthorization, and payment.

Reviewed literature emphasized the importance of establishing agreed-upon goals for automation. ${ }^{12,61}$ Given the state of automation in health care, two potential goals could be to (1) expand and enhance administrative and operational workflows (e.g., improving efficiency or reducing manual processes) while focusing on training the workforce into new roles; and (2) identify opportunities to automate the workflows that have not experienced a great deal of automation in health care. Obtaining interdisciplinary input and perspective across the health care industry to refine and implement automation around these goals are essential as illustrated by the reviewed literature. ${ }^{117,118}$

Use of automation in health care requires attention to several considerations of paramount importance when deciding to automate a workflow and selecting its level of automation. First, the degree to which a human is needed "in the loop" to review, make decisions, and apply judgement at critical workflow decision points will inform whether a workflow should have low, semi-, or full automation. The 
literature showed that a poorly automated workflow can affect quality and trust $45,50,55,60,61$ and, in contrast to other industries, such as manufacturing, health care providers, staff, and patients contribute to a co-produced service involving coordination, communication, and commitment to an intended health goal or status. ${ }^{3,19,84}$ The foundational role of the provider-patient relationship in the human experience of care delivery underscores the importance of selecting workflows to automate that create and maintain trust in the humans and technology involved. Moreover, patient privacy and data security are important considerations in health care delivery, ${ }^{1}$ which calls for a critical need for careful planning and protection in highly automated workflows. Lastly, with the opportunity to apply advanced computational techniques to health care, attention must be paid to ensure such techniques do not perpetuate existing biases in health and health care nor create new ones.

We found that priorities, goals, and outcomes were driving forces for automation across industries. ${ }^{27,44,60,110}$ With a multitude of stakeholders within health care, there may be conflicting automation needs and goals. There are opportunities for automation to support needs of many stakeholders, including administration and administrative staff, many types of clinicians, allied health professionals, patients and caregivers, and public health experts. It will be important to balance conflicting needs and goals when multiple stakeholders are part of the same workflow. In addition, incentives to encourage automation may propel its adoption, particularly for specific workflows, such as population health, where the benefits and value are derived by stakeholders who have not financed automation.

In addition, workflows being automated may require redesign as part of the implementation process. Any redesign should build on the established automation goals and desired outcomes, with a focus on the effectiveness and efficiency of current workflows and how automation would support and work as part of redesigned workflows. Similar to recommended best practices in health IT design and implementation, ${ }^{119,120}$ this will require analyzing current workflows and mapping proposed workflows, while considering the roles, needs, and responsibilities of multiple stakeholders that may be involved.

Successful design and implementation of automation in workflow will require a robust technical infrastructure that can support desired automation activities. This may require health care organizations to analyze current infrastructure and its capabilities to sustain or support automation solutions or technologies being considered or designed.

Many examples from the literature focused on automated workflows at a single organization or across an enterprise, but not across an entire industry. ${ }^{18,20,22,58,86,97,121}$ For widespread gains within the health care delivery system, it is important that automation efforts can scale across health care, and lessons learned from the development of health information exchanges may offer some insights on what may and may not work in trying to make industrywide gains on automation in health care. ${ }^{122}$ Some industries, such as manufacturing and finance, have experienced widespread gains through automation, following collective efforts to address common needs. ${ }^{24,27,123}$ In health care, there is an opportunity to make gains across organizations or stakeholders to have an impact; it will be important to identify and understand what opportunities exist across the industry.

\section{Future Directions and Conclusion}

The reviewed literature clearly points to a set of factors to consider when automating workflows. In particular, there are attributes that make certain workflows more apt for automation such as frequency, roles, and responsibilities being clearly defined, and being manual or characterized by high data entry. That said, we identified a continuum of automation examples that varied depending on task and technology characteristics. This included workflow automation that had "humans in the loop," particularly in highly complex workflows. We found automation is applied for diverse purposes including reducing or eliminating redundant workflows, removing waste, identifying fraud and abuse, improving quality, improving efficiency, or increasing productivity among others.

However, advancing automation in health care will require careful consideration of which workflows to automate, what instrumentation may be required to do so, how automation solutions are developed and implemented, how to measure effectiveness, and who benefits from automation. Efforts to advance automation more broadly will require participation from different stakeholders across health care, including developers, informaticians, researchers, health care practitioners, and policymakers.

In particular, it will be important to evaluate workflows and identify areas of greatest needed. Clearly defining automation goals will be critical to identify and develop relevant solutions, and implementation and evaluation processes. It will be important to thoughtfully advance technology needed to support automation of prioritized workflow. As with any new innovations or technology, advancing automation in health care will require the development of robust and transparent testing and evaluation approaches. Ideally, automation should be designed with closed feedback loops that allow for real-time performance monitoring. Furthermore, the development and implementation of workflow automation in health care will require creation of policies that both allow advancement of automation and include needed safeguards to protect data and assess and mitigate risks. Lastly, as the use of automation increases in health care, it will be important to identify and share relevant best practices broadly. These efforts will require health care stakeholders to invest and reinforce the necessary infrastructure and resources to support development, evaluation, and implementation of automation approaches.

With continued concerns regarding quality, effectiveness, efficiency, safety, and patient-centeredness of health care, automation of workflow that leverages modern computing capabilities offers an opportunity to address relevant concerns while benefiting from pertinent advancements from outside of health care. As part of its effort to advance 
workflow automation in health care, ONC will use insights gained from other industries along with discussions with key informants and a multidisciplinary workshop to inform priorities for health care workflow automation.

\section{Clinical Relevance Statement}

Advancements in modern computing have created new opportunities to leverage automation to improve the way care is delivered by providers, and the way health is managed by patients. Developing and implementing workflow automation in health care might benefit from leveraging lessons learned from other industries. This article summarizes the extent of workflow automation in other industries, characterizes how workflows are automated, and identifies design and implementation considerations to better support the implementation of workflow automation in health care.

\section{Multiple Choice Questions}

1. What is the purpose of the effort ONC is leading to advance workflow automation in health care?

a. To develop an artificial intelligence engine to be implemented in electronic health record systems across the United States.

b. To establish priorities for workflow automation by using modern computing.

c. To advance standards that enable electronic health data sharing for clinical care and research.

d. To develop a clinical avatar that will support patients and caregivers in managing their health.

Correct Answer: The correct answer is option b. ONC is leading a project that will establish priorities to advance workflow automation in health care. The project will identify opportunities for automation in health care in both clinical and administrative areas; explore what would need to be instrumented to enable such automation; explore the need for new and/or updated workflows; and introduce perspectives from other industries such as finance, hospitality, and manufacturing. ${ }^{31}$

2. What are characteristics of tasks within a workflow that are best suited to full automation?

a. Manual tasks that repeat infrequently.

b. Tasks that have frequently shifting roles and responsibilities.

c. Tasks with complex decision rules.

d. Simple and clear tasks.

Correct Answer: The correct answer is option d. Manual tasks that repeat frequently, have concrete and welldefined roles, and responsibilities, and have simple decision rules are best suited for full automation. By contrast, tasks that repeat infrequently, have shifting responsibilities that are not well defined, and require a high degree of human cognition or intervention to navi- gate complex decision-making are generally associated with low automation. ${ }^{31}$

Protection of Human and Animal Subjects

There were no human and/or animal subjects included in this literature review.

\section{Authors' Contributions}

T.Z.C., S.N.H., and N.K. led the conception of the article. All authors revised the article critically and provided intellectual content, and they also approved the final version for submission. The order of authors listed in the manuscript has been approved by all authors.

\section{Funding}

This work was partially funded through U.S. Department of Health and Human Services contract number HHSP233201600030I, task order number: HHSP75P00119F 37001 with Clinovations Government + Health.

Conflict of Interest

None declared.

\section{Acknowledgments}

The authors thank Jane Bryant for copy editing support, Maureen Tan for reference formatting assistance, and Raj Ratwani, PhD, MedStar Health Research Institute and MedStar Health National Center for Human Factors in Healthcare for his valuable advice on this document. We also thank Tracy Okubo from the Office of the National Coordinator for Health Information Technology; Anita Samarth and Crystal Kallem from Clinovations Government + Health; and Laura Marcial, PhD, from RTI International for leadership and contributions on the overarching project that examined the use of workflow automation in health care.

\section{References}

1 Institute of Medicine (US) Committee on Quality of Health Care in America. Crossing the Quality Chasm: A New Health System for the 21st Century. Washington (DC): National Academies Press (US); 2001

2 Institute of Medicine (US) Committee on Quality of Health Care in America. Kohn LT, Corrigan JM, Donaldson MS, eds. To Err is Human: Building a Safer Health System. Washington (DC): National Academies Press (US); 2000

3 Cain C, Haque S. Advances in Patient Safety: Organizational workflow and its impact on work quality. In: Hughes RG, ed. Agency for Healthcare Research and Quality. 2008

4 National Healthcare Quality and Disparities Reports (NHQDR). AHRQ.gov Published July 2018. Accessed February 4, 2021 at: https://www.ahrq.gov/cpi/about/otherwebsites/nhqrnet.ahrq. gov/NHQRDR.html

5 Makary MA, Daniel M. Medical error-the third leading cause of death in the US. BMJ 2016;353:i2139

6 International Society of Automation. What is automation? Accessed July 7, 2020 at: https://www.isa.org/about-isa/whatis-automation/

7 Agency for Healthcare Research and Quality. What is workflow? Accessed April 17, 2021 at: https://digital.ahrq.gov/health-it- 
tools-and-resources/evaluation-resources/workflow-assessment-health-it-toolkit/workflow

8 airSlate. Why workflow automation is the best medicine for healthcare organizations. Published January 2, 2020. Accessed January 21, 2021 at: https://blog.airslate.com/automationhealthcare-organizations/

9 Workflow peaks and pratfalls. Health Manag Technol 2014;35 (12):8-9

10 Kane C, Mahishi S. Automation of scheduling in healthcare. Managed Healthcare Executive Published May 23, 2020. Accessed April 21, 2021 at: https://www.managedhealthcareexecutive.com/view/automation-scheduling-healthcare

11 Jones BE, Haroldsen C, Madaras-Kelly K, et al. In data we trust? Comparison of electronic versus manual abstraction of antimicrobial prescribing quality metrics for hospitalized veterans with pneumonia. Med Care 2018;56(07):626-633

12 Extending IT services to business process automation: Howard County uses an IT management platform to create a services portal and streamline IT and business workflows. Government Technology. 2018;31(02):46

13 Ahlen A, Akerberg J, Eriksson M, Isaksson AJ, Iwaki T, Johansson $\mathrm{KH}$. Toward wireless control in industrial process automation: a case study at a paper mill. IEEE Contr Syst Mag 2019;39(05): 36-57

14 Byers C. Five ways to automate government workflow. Am City County 2018;133(08):14

15 Kompella L. EGovernance systems as socio-technical transitions using multi-level perspective with case studies. Technol Forecast Soc Change 2017;123:80-94

16 Gavel Y. Bringing the national interlending system into the local document supply process - a Swedish case study. Interlend Doc Supply 2015;43:104-109

17 Seiger R, Assmann U, Huber S. A case study for workflow-based automation in the Internet of things, 2018 IEEE International Conference on Software Architecture Companion (ICSA-C), Seattle, WA. 2018:11-18. Accessed February 9, 2021 at: https:// ieeexplore.ieee.org/document/8432166

18 Mirasol F. Automating the biomanufacturing process. Biopharm Int 2019;32(03):26-30

19 Cid-de-la-Paz V, Jiménez-Ramírez A, Escalona MJ. An automatic and intelligent system for integrated healthcare processes management. In: Rojas I, Ortuño F, eds. Bioinformatics and Biomedical Engineering. IWBBIO 2017102092017621-630

20 Romão M, Costa J, Costa CJ. Robotic process automation: a case study in the banking industry. 2019 IEEE 14th Iberian Conference on Information Systems and Technologies . Accessed February 9, 2021 at: https://ieeexplore.ieee.org/document/ 8760733

21 Lapão LV. The future impact of healthcare services digitalization on health workforce: the increasing role of medical informatics. Stud Health Technol Inform 2016;228:675-679

22 Tabbone G, Egodage K, Schulz K, Garetto A. On the road to automated production workflows in the back end of line. In: Behringer UFW, Finders J, eds. 34th European Mask and Lithography Conference. Proceedings of SPIE 2018; 107752018. Accessed February 9, 2021 at: https://ui.adsabs.harvard.edu/ abs/2018SPIE10775E..0NT/abstract

23 Fluss D. Smarter bots mean greater innovation, productivity, and value: robotic process automation is allowing companies to reimagine and re-invest in all aspects of their businesses. CRM Magazine. 2018;22(10):38-39

24 Grant Thornton. Helping organizations embrace robotic process automation. HFMA (Healthcare Financial Management Association). Published November 30, 2018. Accessed February 2, 2021 at: https://www.hfma.org/topics/hfm/2018/december/62480. html

25 Tilley J. Automation, Robots, and the Factory of the Future. McKinsey \& Company; 2020
26 Greenfield D. 5 keys to automated quality inspection. Automation World. Published May 5, 2015. Accessed February 4, 2021 at: https://www.automationworld.com/products/control/blog/ 13313588/5-keys-to-automated-quality-inspection

27 Ball M. Wonderful workflows. Credit Union Management. 2015; 38(10):36-38

28 Henry J, Pylypchuk Y, Searcy T, Patel V. Adoption of electronic health record systems among U.S. non-federal acute care hospitals: 2008-2015. ONC Data Brief 201635

29 Office of the National Coordinator for Health Information Technology. Office-based physician electronic health record adoption. Health IT Quick-Stat \#50 HealthIT.gov. Published January 2019. Accessed February 4, 2021 at: https://dashboard.healthit. gov/quickstats/pages/physician-ehr-adoption-trends.php

30 Office of the National Coordinator for Health Information Technology. About ONC HealthIT.gov. Published 2020. Accessed February 4, 2021 at: https://www.healthit.gov/topic/about-onc

31 Office of the National Coordinator for Health Information Technology. Health Information Technology Workflow Automation Policy Development. HealthIT.gov. Published 2020. Accessed February 4, 2021 at: https://www.healthit.gov/topic/scientificinitiatives/health-information-technology-workflow-automation-policy-development

32 Clinovations Government + Health under Contract No. HHSP233201600030I. Health IT workflow automation policy development: Industry lessons for healthcare. In: Office of the National Coordinator for Health Information Technology. ed. Washington, D.C.; 2021. Accessed July 28, 2021 at: https:// www.healthit.gov/topic/scientific-initiatives/health-information-technology-workflow-automation-policy-development

33 Higher Education Statistics Agency. (HESA). HESA.ac.uk. JACS 3.0: principal subject codes Accessed July 7, 2020 at:https:// www.hesa.ac.uk/support/documentation/jacs/jacs3-principal

34 Leavitt HJ. Applied organizational change in industry: structural, technical and human approaches. In: Cooper W, Leavitt H, Shelly M, eds. New Perspectives in Organization Research. New York: John Wiley; 1964

35 Aguirre S, Rodriguez A. Automation of a business process using robotic process automation (RPA): a case study. Applied Computer Sciences in Engineering. Commun Comput Inf Sci 2017; 742:65-71

36 Toews R. AI will transform the field of law. Forbes. Published December 19, 2019. Accessed July 7, 2020 at: https://www. forbes.com/sites/robtoews/2019/12/19/ai-will-transform-thefield-of-law/\#11e491f67f01

37 Zhou W. The impact of AI on the hospitality industry. Towards data science. Published November 28, 2019. Accessed July 7, 2020 at: https://towardsdatascience.com/the-impact-of-ai-onthe-hospitality-industry-8ba7adb66be

38 Murawski J. Uber IPO highlights the company's AI brain. Wall Street Journal . Published April 15, 2019. Accessed July 7, 2020 at: https://www.wsj.com/articles/uber-ipo-highlights-the-companys-ai-brain-11555320601

39 McClure D. The many faces of workflow. Account Today 2014;28 (08):26-31

40 McQuilken T. Automation is the future of print workflows. Editor \& Publisher. 2014;147(01):32-33

41 Schleifer D. Handling complexity with workflow automation. TVB Europe 2017:37

42 Schmidt S, Goros M, Parsons HM, et al. Improving initiation and tracking of research projects at an academic health center: a case study. Eval Health Prof 2017;40(03):372-379

43 Guerra L, Sousa SD, Nunes EP. Statistical process control automation in the final inspection process: an industrial case study. In: IEEE. 2016:876-80

44 Spjuth O, Bongcam-Rudloff E, Hernández GC, et al. Experiences with workflows for automating data-intensive bioinformatics. Biol Direct 2015;10(01):43 
45 Holzmüller-Laue S, Göde B, Fleischer H, Thurow K. Improved compliance by BPM-driven workflow automation. J Lab Autom 2014;19(06):528-545

46 Holzmüller-Laue S, Göde B, Thurow K. Flexible End2End workflow automation of HIT-discovery research. J Lab Autom 2014;19 (04):349-361

47 Hernandez R. Boosting bioproduction workflows with automation technologies. Pharm Technol 2017;41(06):16-19

48 Benta D, Rusu L, Manolescu MJ. Workflow automation in a risk management framework for pavement maintenance projects. Int J Comput Commun Control 2017;12(02):155-165

49 Cut administrative spending with automation: Stop leaving money on the table. Receivables Report for America's Health Care Financial Managers. 2019;34(05):3-4

50 Making the case for DC workflow automation to drive process optimization. Mod Mater Handl. 2017;72(04):34-35

51 Barlow RD. RFID: What's the frequency, healthcare? Healthcare Purchasing News 2019;43(09):42-44

52 Waszkowski R, Nowicki T, Worwa K. Corporate efficiency improvement with business process automation. MATEC Web Conf $2018 ; 210: 02012$. Accessed February 9, 2021 at: https://www. mendeley.com/catalogue/de387ceb-ff03-38a7-94af042ca5d46f42/

53 Sala Benito JV, Paini A, Richarz AN, et al. Automated workflows for modelling chemical fate, kinetics and toxicity. Toxicol In Vitro 2017;45(Pt 2):249-257

54 Tuthill JM. Decision support to enhance automated laboratory testing by leveraging analytical capabilities. Clin Lab Med 2019; 39(02):259-267

55 Tacker DH, Topardo J, Mahaffey C, Perrotta PL. Workflow analysis comparing manual and automated specimen processing for mass spectrometry-based vitamin D testing. Lab Med 2014;45(04): 361-367

56 Kuramoto H, Sugimoto N, Iwami Y, Kato C, Hori M, Iida M. Evaluation of a new automated processing system (TACAS ${ }^{\mathrm{TM}}$ Pro) for liquid-based procedures. Acta Cytol 2015;59(02): 207-212

57 Laughlin S. Thriving under pressure: lab information systems can reduce errors and automate workflow. Health Manag Technol 2016;37(05):24

58 Cutler TR. Production automation gets IEs off the shop floor: Technology helps optimize scheduling and workforce in the engineer-to-order space. ISE: Industrial \& Systems Engineering at Work 2017;49(08):47-50

59 Bainbridge L. Ironies of automation. In: Johannsen G, Rijnsdorp JE, eds. Analysis, design and evaluation of man-machine systems: Proceedings of the IFAC/IFIP/IFORS/IEA conference, BadenBaden, Federal Republic of Germany, Sept 27-29, 1982. Pergamon 1983:129-135. Accessed April 17, 2021 at: https://www. sciencedirect.com/science/article/abs/pii/0005109883900468

60 Rodenburg J. Robotic milking: technology, farm design, and effects on work flow. J Dairy Sci 2017;100(09):7729-7738

61 Abollado JR, Shehab E, Bamforth P. Challenges and benefits of digital workflow implementation in aerospace manufacturing engineering. In: Shehab E, Tomiyama T, Lockett H, Salonitis K, Roy R, Tiwari A, eds. Complex Systems Engineering and Development. Proc CIRP 201760 80-85. Accessed February 9, 2021 at: http://toc.proceedings.com/34564webtoc.pdf

62 Weir NM, Newham R, Bennie M. A literature review of human factors and ergonomics within the pharmacy dispensing process. Res Social Adm Pharm 2020;16(05):637-645

63 Tudor J, Klochko C, Patel M, Siegal D. Order entry protocols are an amenable target for workflow automation. J Am Coll Radiol 2018;15(06):854-858

64 Chan-Amaya A, Anaya-Pérez ME, Benitez-Baltazar VH. A methodology to determine the level of automation to improve the production process and reduce the ergonomics index. J Phys Conf Ser 2017;885:012013
65 Al Aani S, Bonny T, Hasan SW, Hilal N. Can machine language and artificial intelligence revolutionize process automation for water treatment and desalination? Desalination 2019; 458:84-96

66 Bien-Aime V. Leveraging workflow automation in the appraisal management process. Mortgage Banking 2016;76(06):106-107

67 Ford M. (I, Robot), NOT: as industrial engineering evolves into "digital engineering," will the automated factory work for the workers? Printed circuit design \& fab. Circuits Assem 2018;35 (01):24-26

68 Spinks J, Jackson J, Kirkpatrick CM, Wheeler AJ. Disruptive innovation in community pharmacy - Impact of automation on the pharmacist workforce. Res Social Adm Pharm 2017;13 (02):394-397

69 Harlan J. Workflow automation: a collective case study, ProQuest Information \& Learning [dissertation]. Dissertation Abstracts International: Section $\mathrm{B}$ : The Sciences and Engineering 2014;74(12-B)(E). Accessed February 9, 2021 at: https://eric. ed.gov/?id=ED560289

70 De Ramón Fernández A, Ruiz Fernández D, Sabuco García Y. Business process management for optimizing clinical processes: a systematic literature review. Health Informatics J 2020;26(02): 1305-1320

71 Chen J, Sun L, Guo C, Wei W, Xie Y. A data-driven framework of typical treatment process extraction and evaluation. J Biomed Inform 2018;83:178-195

72 Maia C, Botta C, Ruiz CP, et al. FlowCT: a semi-automated workflow for deconvolution of immunophenotypic data and objective reporting on large datasets. Clin Lymphoma Myeloma Leuk 2019;19:94

73 Zagoudis J. Automated treatment planning system streamlines workflow. ITN. Published July 3, 2018. Accessed July 8, 2020 at: https://www.itnonline.com/article/automated-treatment-planning-system-streamlines-workflow

74 Slovis BH, Nahass TA, Salmasian H, Kuperman G, Vawdrey DK. Asynchronous automated electronic laboratory result notifications: a systematic review. J Am Med Inform Assoc 2017;24(06): 1173-1183

75 Scheinfeld MH, Kaplun O, Simmons NA, Sterman J, GoldbergStein S. implementing a software solution across multiple ultrasound vendors to auto-fill reports with measurement values. Curr Probl Diagn Radiol 2019;48(03):216-219

76 Baur C, Wee D. Manufacturing's next act. McKinsey . Published June 2015. Accessed February 26, 2020 at: https://www.mckinsey.com/business-functions/operations/our-insights/manufacturings-next-act

77 Stocker D, Finkenstaedt T, Kuehn B, et al. Performance of an automated versus a manual whole-body magnetic resonance imaging workflow. Invest Radiol 2018;53(08):463-471

78 Winkler D, Schönbauer M, Biffl S. Towards automated process and workflow management: a feasibility study on tool-supported and automated engineering process modeling approaches. In: Rabiser R, Torkar R, eds. 2014 40th EUROMICRO Ereference on Software Engineering and Advanced Applications. IEEE 2014;102-110. Accessed February 9, 2021 at: https:// ieeexplore.ieee.org/document/6928797/footnotes\#footnotes

79 Sandia National Laboratory Clay RL. Workflow automation today and tomorrow (presentation). 2018. SAND2018-3613C

80 Riben M. Laboratory automation and middleware. Surg Pathol Clin 2015;8(02):175-186

81 Al-Barakati A, White M, Patoli Z. The application of workflow management to digital heritage resources. Int J Inf Manage 2014; 34(05):660-671

82 Florea AMI, Diaconita V, Dorobat I. Business process modeling for sales processes automation. In: Bilgin MH, Danis H, eds. Entrepreneurship, Business and Economics, Vol 1. Eurasian Studies in Business and Economics. Cham, Switzerland: Springer International Publishing; 2016:375-383 
83 O'Connor AM, Tsafnat G, Gilbert SB, Thayer KA, Wolfe MS. Moving toward the automation of the systematic review process: a summary of discussions at the second meeting of International Collaboration for the Automation of Systematic Reviews (ICASR). Syst Rev 2018;7(01):3

84 Katzman M, Kim J, Lesher MD, et al. Customizing an electronic medical record to automate the workflow and tracking of an antimicrobial stewardship program. Open Forum Infect Dis 2019;6(08):ofz352

85 Reisinger E, Genthner L, Kerssemakers J, et al. OTP: an automatized system for managing and processing NGS data. J Biotechnol 2017;261:53-62

86 Gambone Hudson A, Curtis R. Before automating the blood bank, evaluate compatibility with existing systems. MLO Med Lab Obs 2017;49(03):42

87 Melnick ER, Dyrbye LN, Sinsky CA, et al. The association between perceived electronic health record usability and professional burnout among US physicians. Mayo Clin Proc 2020;95(03):476-487

88 Shailam R, Botwin A, Stout M, Gee MS. Real-time electronic dashboard technology and its use to improve pediatric radiology workflow. Curr Probl Diagn Radiol 2018;47(01):3-5

89 Yu HE, Lanzoni H, Steffen T, et al. Improving laboratory processes with total laboratory automation. Lab Med 2019;50(01):96-102

90 Abubaker H, Salah KIEEE. Workflow automation for partially hosted cloud services. In: IEEE 2nd International Workshops on Foundations and Applications of Self* Systems (FAS*W), Tuscon, AZ: IEEE; September 2017:149-154

$91 \mathrm{Wu}$ H, Kshirsagar A, Nwala A, Yaohang L. Teaching information security with workflow technology-A case study approach. J Inf Syst Educ 2014;25(03):201-210

92 Bevilacqua M, Ciarapica FE, De Sanctis I, Mazzuto G, Paciarotti C. The automation of an assembly system: a business process reengineering (BPR) perspective. In: Framinan JM, Gonzalez PP, Artiba A, eds. Industrial Engineering and Systems Management (IESM). 2015 International conference Proceedings 2015;371377. Accessed February 9, 2021 at: https://ieeexplore.ieee.org/ document/7380185

93 Johnston C. Automating the workforce: Changing tides in the water utility industry. WaterWorld 2017;33(05):10-14

94 Vannetti F, Atzori T, Matteoli S, et al. Ergonomics and workflow evaluation of automatic doppler angle technology implemented in a diagnostic ultrasound system. In: Ahram T, Karwowski W, Schmorrow D, eds. 6th International conference on Applied Human Factors and Ergonomics. Procedia Manuf 20153120-127

95 Frolova MA, Razumova TA. The use of process approach to base the need of automation of business processes in educational institutions. In: Kiselev BG and Panin OA. eds. Information Technologies in Education of the XXI Century. AIP conference Proceedings 2017;1797. Accessed February 9, 2021 at: https:// aip.scitation.org/doi/abs/10.1063/1.4972460

96 Chen AM, Kupelian PA, Wang PC, Steinberg ML. Development of a radiation oncology-specific prospective data registry for research and quality improvement: a clinical workflow-based solution. JCO Clin Cancer Inform 2018;2:1-9

97 Martinho R, Rijo R, Nunes A. Complexity analysis of a business process automation: case study on a healthcare organization. Procedia Comput Sci 2015;64:1226-1231

98 Campos M. Automation and manufacturing innovations for the food industry: recent case studies in the food industry highlight how new innovations can improve the automation, manufacturing, and packaging processes. Mach Des 2018;90(05):72-73

99 Dias KN, Welfer D, Cordeiro d'Ornellas M, Pereira Haygert CJ, Dotto GN. Use of flowchart for automation of clinical protocols in mHealth. Stud Health Technol Inform 2017;245:59-63

100 Desai V, Flanders A, Zoga AC. Leveraging technology to improve radiology workflow. Semin Musculoskelet Radiol 2018;22(05): 528-539
101 Laing GL, Bruce JL, Skinner DL, Allorto NL, Clarke DL, Aldous C. Development, implementation, and evaluation of a hybrid electronic medical record system specifically designed for a developing world surgical service. World J Surg 2014;38(06): 1388-1397

102 Kattepur A. Towards structured performance analysis of industry 4.0 workflow automation resources. In: Proceedings of the 2019 ACM/SPEC International conference on Performance Engineering. ACM 2019:189-196. Accessed February 9, 2021 at: https://dl.acm.org/doi/10.1145/3297663.3309671

103 Messinger BL, Rogers DN, Hawker CD. Automation and process re-engineering work together to achieve Six Sigma quality: a 27year history of continuous improvement. Lab Med 2019;50(02): e23-e35

104 Minor M, Bergmann R, Görg S. Case-based adaptation of workflows. Information Systems. Inf Syst 2014;40:142-152

105 Kalejta CD, Higgins S, Kershberg H, et al. Evaluation of an automated process for disclosure of negative noninvasive prenatal test results. J Genet Couns 2019;28(04):847-855

106 Meier J, Boehm A, Kielhorn A, Dietz A, Bohn S, Neumuth T. Design and evaluation of a multimedia electronic patient record "oncoflow" with clinical workflow assistance for head and neck tumor therapy. Int J CARS 2014;9(06):949-965

107 Covington EL, Chen X, Younge KC, et al. Improving treatment plan evaluation with automation. J Appl Clin Med Phys 2016;17(06): 16-31

108 Britan A, Cusin I, Hinard V, et al. Accelerating annotation of articles via automated approaches: evaluation of the neXtA5 curation-support tool by neXtProt. Database (Oxford) 2018; 2018:bay 129

109 Nguyen D, Gadhamshetty V, Nitayavardhana S, Khanal SK. Automatic process control in anaerobic digestion technology: a critical review. Bioresour Technol 2015;193:513-522

110 Du L, Jiang ZF. Analysis and design of library office automation system based on workflow. In: Jiang Z, Liu X, Han J, eds. Engineering Solutions for Manufacturing Processes IV, Pts 1 and 2. Adv Mat Res 2014;889-890:1301-1305. Accessed February 9, 2021 at: https://www.scientific.net/AMR.889-890.1301

111 Schneider PJ, Pedersen CA, Scheckelhoff DJ. ASHP national survey of pharmacy practice in hospital settings: dispensing and administration-2017. Am J Health Syst Pharm 2018;75(16): $1203-1226$

112 UNC Health Care and UNC School of Medicine Newsroom. The TUG robots are coming. Published December 19, 2019. Accessed January 24, 2021 at: https://news.unchealthcare.org/2018/01/ the-tug-robots-are-coming/

113 Lloyd JK, Ahrens EA, Clark D, Dachenhaus T, Nuss KE. Automating a manual sepsis screening tool in a pediatric emergency department. Appl Clin Inform 2018;9(04):803-808

114 O'Connor SD, Khorasani R, Pochebit SM, Lacson R, Andriole KP, Dalal AK. Semiautomated system for nonurgent, clinically significant pathology results. Appl Clin Inform 2018;9(02): 411-421

115 Tso GJ, Tu SW, Oshiro C, et al. Automating guidelines for clinical decision support: knowledge engineering and implementation. AMIA Annu Symp Proc 2017;2016:1189-1198

116 Kilsdonk E, Peute LW, Jaspers MWM. Factors influencing implementation success of guideline-based clinical decision support systems: a systematic review and gaps analysis. Int J Med Inform 2017;98:56-64

117 Keil M. Workflow optimization and process automation in dialysis wards by introducing a treatment monitoring system. Nephrol Dial Transplant 2015;30(Suppl 3):761

118 De Pourcq K, Gemmel P, Devis B, Van Ooteghem J, De Caluwé T, Trybou J. A three-step methodology for process-oriented performance: how to enhance automated data collection in healthcare. Inform Health Soc Care 2019;44(03):313-325 
119 Agency for Healthcare Research and Quality. Workflow assessment for health IT toolkit. Accessed April 17, 2021 at: https:// digital.ahrq.gov/health-it-tools-and-resources/evaluationresources/workflow-assessment-health-it-toolkit

120 Carayon P, Karsh BT, Cartmill RS, et al. Summary report: Incorporating health information technology into workflow redesign. AHRQ Prepared by: Center for Quality and Productivity Improvement, University of Wisconsin-Madison, under Contract No. HHSA 290-2008-10036C. AHRQ Publication No. 10-0098-EF. October 2010. Accessed April 17, 2021 at: https://digital.ahrq.gov/sites/ default/files/docs/citation/workflowsummaryreport.pdf
121 Suica D. Plan to learn about automating processes. Production Machining. Published July 20, 2018. Accessed July 8, 2020 at: https://www.productionmachining.com/columns/plan-to-learnabout-automating-processes

122 Holmgren AJ, Adler-Milstein J. Health information exchange in US hospitals: the current landscape and a path to improved information sharing. J Hosp Med 2017;12(03):193-198

123 Smith A, Anderson M. Americans and automation in everyday life. Pew Research Center. Published October 4, 2017. Accessed February 4, 2021 at: https://www.pewresearch.org/internet/ 2017/10/04/automation-in-everyday-life/ 